\title{
Author Correction: Hippocampal neurons represent events as transferable units of experience
}

Chen Sun (D), Wannan Yang, Jared Martin and Susumu Tonegawa (D)

Correction to: Nature Neuroscience https://doi.org/10.1038/s41593-020-0614-x, published online 6 April 2020.

In the version of this article initially published, Figs. $3 \mathrm{~d}$ and $6 \mathrm{i}$ showed incorrect graphs. No statistics or conclusions were changed or affected. The errors have been corrected in the PDF and HTML versions of this article.

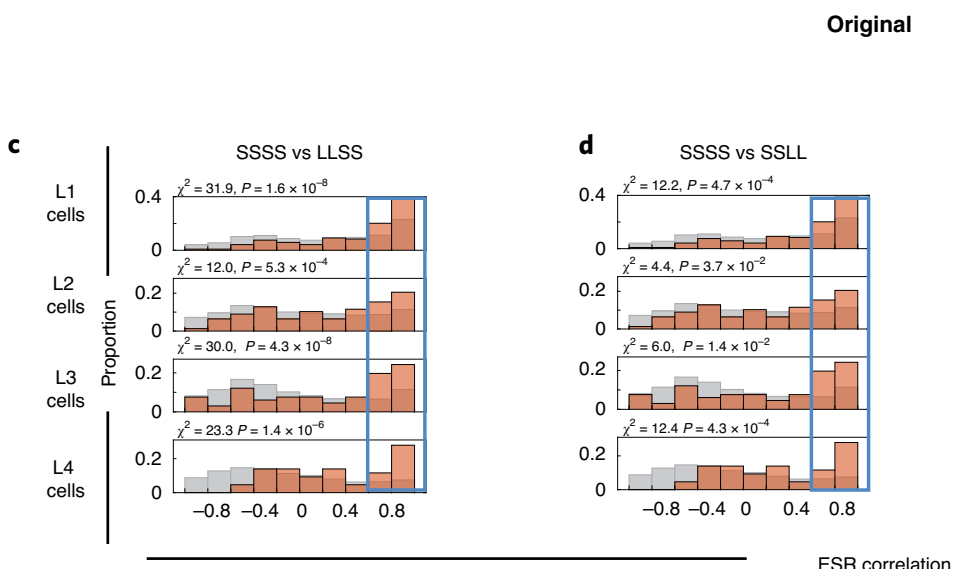

Corrected

C

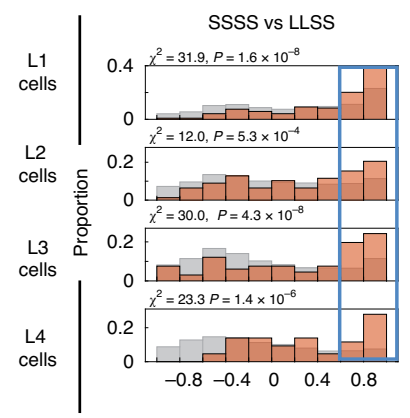

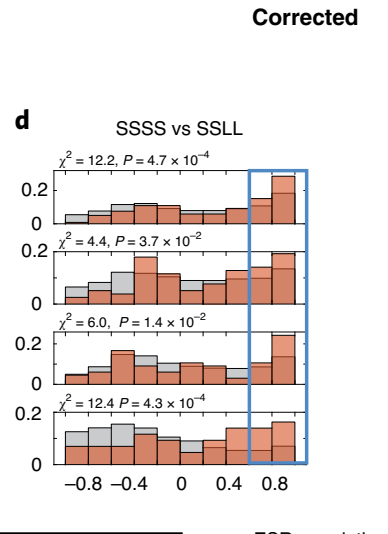

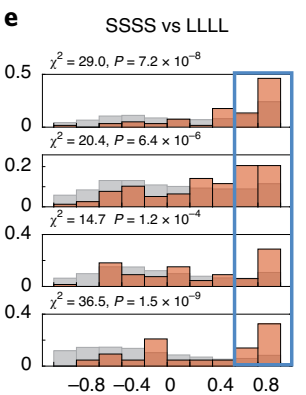

$\square$ Shuffle

f SSLL vs LLSS

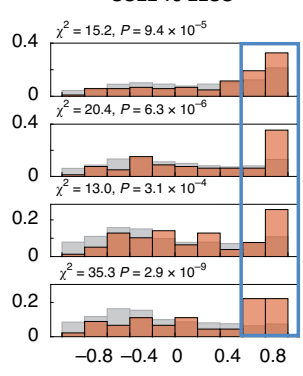

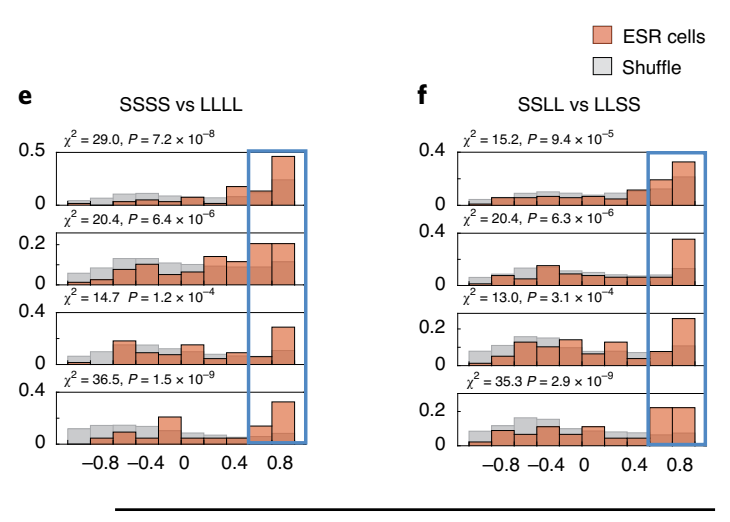

Fig. 3 | Original and Corrected.

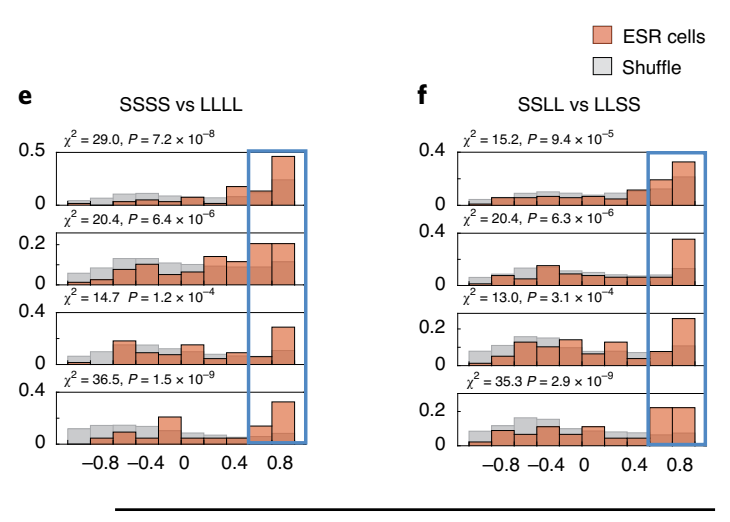

ESR correlation 


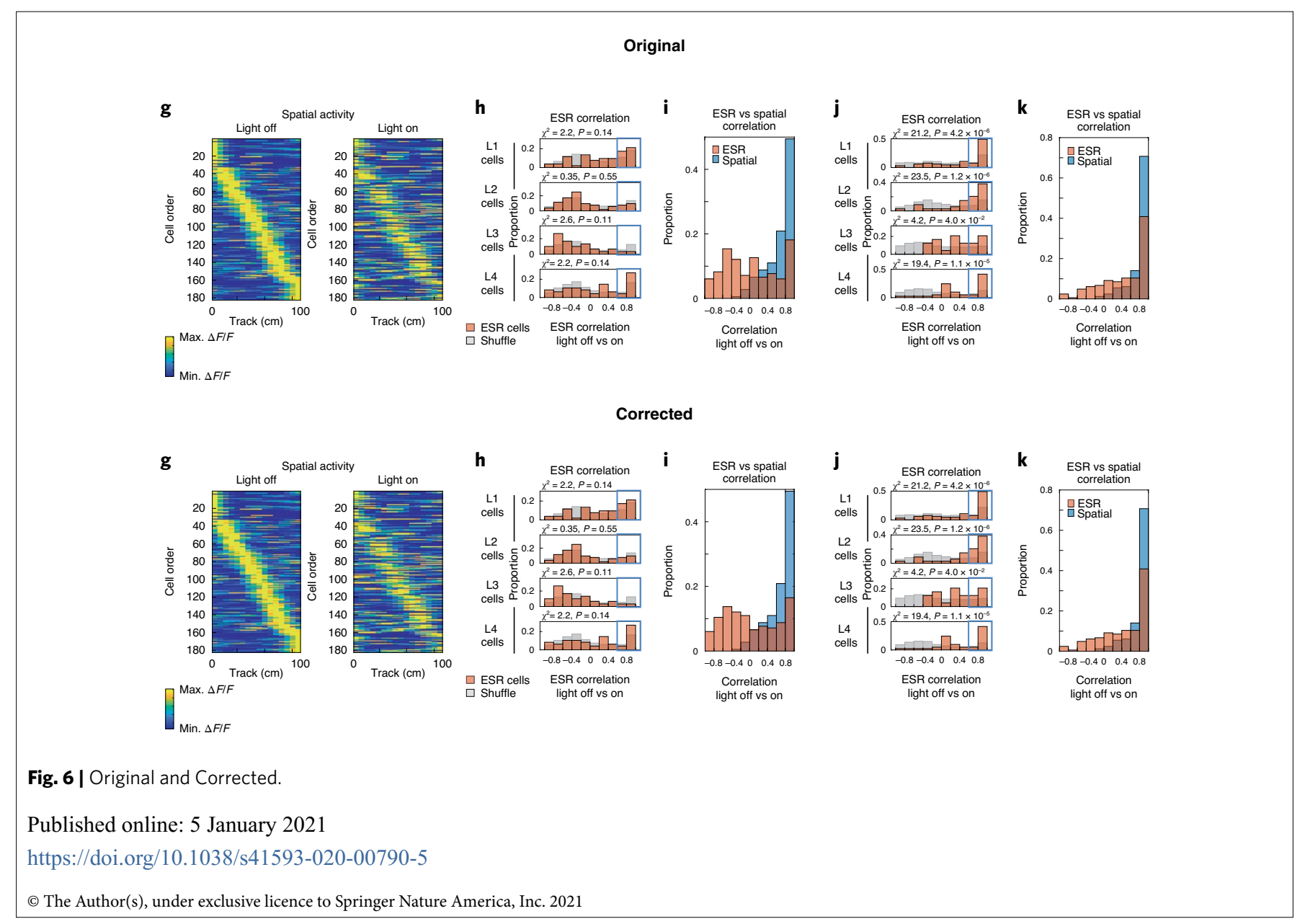

\section{Publisher Correction: Diversity and dynamism in the cerebellum}

\section{Chris I. De Zeeuw (D), Stephen G. Lisberger (D) and Jennifer L. Raymond (D)}

Correction to: Nature Neuroscience https://doi.org/10.1038/s41593-020-00754-9, published online 7 December 2020.

In the version of this article initially published, in the section "Wiring diagram" the sentence beginning "These newly discovered recurrent pathways..." was repeated; and in the x paragraph of the section "Acquisition versus consolidation" the sentence beginning "A genetic modification..." should have read, "A genetic modification that causes climbing fibers to be directed to the ipsilateral, rather than contralateral, cerebellar cortex, reverses the direction selectivity of the climbing fiber responses of their Purkinje cell targets and, concomitantly, reverses the direction selectivity of their simple spike responses." These errors have been corrected in the PDF and HTML versions of this article.

Published online: 4 January 2021

https://doi.org/10.1038/s41593-020-00782-5

(c) Springer Nature America, Inc. 2021 